\title{
Research HealthSWEDE: Costs With Sublingual Immunotherapy - A Swedish Questionnaire Study
}

Petter Olsson ( $\square$ petter.olsson@ki.se )

Karolinska institutet Department of Clinical Sciences Intervention and Technology https://orcid.org/0000-0002-3913-3914

\section{Carl Sköder}

Skanes universitetssjukhus Lund Clinical sciences

\section{Lars Ahlbeck}

Universitetssjukhuset i Linkoping Allergy Center

\section{Frida Hjalte}

The Swedish Insitute for Health Economics

\section{Karl-Olof Welin}

The Swedish Institute for Health Economics

\section{Ulla Westin}

Skanes universitetssjukhus Lund

\section{Morgan Andersson}

Skanes universitetssjukhus Lund

\section{Cecilia Ahlström Emanuelsson}

Skanes universitetssjukhus Lund

\section{Lars-Olaf Cardell}

Karolinska institutet Department of Clinical Sciences Intervention and Technology

\section{Research}

Keywords: Absenteeism, direct costs, presenteeism, allergic rhinitis, indirect costs

Posted Date: June 8th, 2020

DOl: https://doi.org/10.21203/rs.3.rs-33079/v1

License: (9) This work is licensed under a Creative Commons Attribution 4.0 International License. Read Full License

Version of Record: A version of this preprint was published at Allergy, Asthma \& Clinical Immunology on June 7th, 2021. See the published version at https://doi.org/10.1186/s13223-021-00560-3. 


\section{Abstract}

\section{Background}

The aim of this cross-sectional survey was to compare the health-economic consequences for allergic rhinitis (AR) patients treated with sublingual Immunotherapy (SLIT) in terms of direct and indirect costs with a reference population of patients receiving standard of care pharmacological therapy.

\section{Methods}

Primary objective was to analyse the health-economic consequences of SLIT for grass pollen allergy in Sweden vs reference group waiting for subcutaneous immunotherapy (SCIT). A questionnaire was mailed to two groups of AR patients.

\section{Results}

The questionnaire was distributed to 548 patients, 307 with SLIT and 241 in reference group (waiting for SCIT). Response rate was $53.8 \%$. Mean annual costs were higher for reference patients than SLIT group; $€ 3907$ (SD 4268) vs $€ 2084$ (SD 1623) $p<0.001$. Mean annual direct cost was higher for SLIT-patients, $€$ 1191 (SD 465) than for reference, $€ 751$ (SD 589) $p<0.001$. Mean annual indirect costs for combined absenteeism and presenteeism were lower for patients treated with SLIT, € 912 (SD 1530), than for reference, $€ 3346$ (SD 4120) $p<0.001$, with presenteeism as main driver.

\section{Conclusions}

SLIT seems to be a cost-beneficial way to treat seasonal AR. This information might be used to guide future recommendations.

\section{Background}

Allergic rhinitis (AR) is a global health problem with adverse impact on sleep, cognitive function, mood, and comorbid conditions, such as asthma [1]. The prevalence in Sweden is approximately $30 \%$ with birch and grass pollen as the dominating allergens [2]. AR causes, on top of the individual burden, additional costs at a societal level, particularly in terms of increased healthcare utilization, reduced productivity and impairment activities of daily living. Effects on society, in terms of work absence (absenteeism), impaired work productivity while at work (presenteeism), as well as loss of school days, have recently been acknowledged as an issue [3], even though the scientific knowledge in the field is still scarce.

Intranasal corticosteroids and oral and/or ocular antihistamines constitute the foundation of AR treatment, sometimes with the addition of systemic steroids when seasonal symptom control fails. However, allergen immunotherapy (AIT) is the only therapy that, besides alleviating symptoms, also appears to improve the long-term development of the disease [4]. Subcutaneous immunotherapy (SCIT) has been used for decades, whereas sublingual immunotherapy (SLIT) has been available for about 
10 years. Both therapies have been proven efficacious in the treatment of pollen induced symptoms, but their use is limited by drawbacks. SCIT requires, besides an induction period of about three months with weekly physician supervised subcutaneous injections, continued every six to eight weeks during three to four years. SLIT is based on a daily tablet intake during the same period. It has been considered to be a relatively expensive treatment due to the cost of the medication. Previous studies have indicated that AIT might ease the socioeconomic burden caused by AR [5]. Hence, the aim of the present cross-sectional survey, "HealthSWEDE" or Health economy and sublingual immunotherapy in Sweden, was to compare the health-economic consequences for patients treated with SLIT, in terms of direct and indirect costs with patients receiving standard of care pharmacological therapy.

\section{Methods}

\section{Study design and population}

This study was a cross-sectional survey including patients 18-65 years old identified via specialist centres in Sweden. Two groups of patients with specific IgE-confirmed grass pollen allergy were identified; one had received at least 12 months of SLIT treatment against grass pollen allergy, $n=307$, whereas the other cohort of individuals, the reference population, were waiting to start up SCIT against grass pollen and/or birch pollen allergy, $n=241$. During the waiting period the latter group had received standard of care pharmacological treatment. The optimal reference group for the SLIT cohort would have been patients waiting for SLIT, but since SLIT in Sweden usually starts more or less upon referral, there is practically no waiting list for this therapy. Thus, patients waiting for SCIT were used for the comparison.

A questionnaire was mailed, after the birch and grass seasons, to the two groups of AR patients with a valid postal address in Sweden. Distribution was done by regular mail in September 2017 (a postal reminder was sent out approximately 2 weeks after the first letter) to capture the seasonal allergies season from March to August the same year. The questionnaire included questions on age, gender, employment status, sick leave, health care resource utilization and quality of life as measured by EQ-5D$3 \mathrm{~L}[6]$.

Inclusion criteria were age 18-65 years, a valid address in Sweden and prick test or specific lgEconfirmed grass pollen allergy. The only exclusion criterion was lack of ability to read and write Swedish.

The primary objective of this cross-sectional survey was to analyse the health-economic consequences in terms of direct and indirect costs and quality of life in the treatment of grass allergy with SLIT for grass pollen allergy in Sweden vs a reference group with standard of care, waiting for SCIT.

\section{Health-economic Analyses}

Direct costs were calculated for pharmaceuticals and for health care contacts (physician visits, nurse visits and telephone consultations). Unit costs for health care contacts were collected from a regional 
price list [7] Unit costs for pharmaceuticals were collected from FASS [8]. Indirect costs or lost productivity due to sick-leave and impaired working capacity were calculated according to the human capital approach [9]. Information on income from work in Sweden was collected from Statistics Sweden and adjusted using the Consumer Price Index (CPI) to 2017 price level [10, 11]. Costs for payroll taxes by 43 percent was added [12]. Swedish costs were converted to Euros, $€$, using the average exchange rate 2017.

When calculating the number of days for questions answered with intervals the middle value for the interval was used. In cases where a response says more than a certain value, the minimum exceeding the value was used to provide a conservative estimate. The relevant pollen season was deemed to last up to four months. When calculating costs related to presenteeism and absenteeism, answers indicating a longer season than four months are set to only include the four months relevant to the pollen season. Costs were not calculated for SCIT treatment in accordance with the definition of the included population.

The maximum occupation level was assumed to be $100 \%$. For respondents reporting several part-time occupations the sum of the part-time occupations was used up to $100 \%$. For respondents reporting a part-time occupation without specifying the extent, a $50 \%$ occupation level was assumed.

The presented mean costs were calculated on a sample limited to the working population, i.e. approximately $80 \%$ of the total study population. This approach was used to avoid skewing the mean total and indirect costs (Appendix, Table E1).

\section{Statistical Analyses}

Descriptive statistical analyses were conducted for all questions in the survey and for direct, indirect and total costs. Differences between groups were assessed with t-tests for continuous variables and Chisquared tests were used for categorical variables. All tests were performed at the 0.05 level of significance and were two-sided.

Statistical analyses were performed using STATA, version 14 for Windows (StataCorp, Stata Statistical Software: Release 14. 2015, StataCorp LP: College Station, TX, USA).

\section{Results}

\section{Sample characteristics}

The questionnaire was distributed to 548 patients, 307 treated with SLIT and 241 in the reference group, waiting for SCIT. The questionnaire was answered by 304 patients out of which 295 fulfilled inclusion criteria, corresponding to a total response rate of $53.8 \%$ (shown in Fig. 1). For details on patient characteristics, please see Table 1. 
Table 1

\begin{tabular}{|c|c|c|c|}
\hline & $\begin{array}{l}\text { Total }(n= \\
\text { 295) }\end{array}$ & $\begin{array}{l}\text { SLIT }(n= \\
177)\end{array}$ & $\begin{array}{l}\text { Reference population } \\
(n=118)\end{array}$ \\
\hline Men/Women & $49 \% / 51 \%$ & $\begin{array}{l}55 \% / \\
45 \%\end{array}$ & $41 \% / 59 \%$ \\
\hline Age, mean years (SD) & $\begin{array}{l}36.5 \\
(11.1)\end{array}$ & $\begin{array}{l}37.2 \\
(11.6)\end{array}$ & $35.3(10.2)$ \\
\hline Employed, n (\%) & $\begin{array}{l}235 \\
(80 \%)\end{array}$ & $\begin{array}{l}146 \\
(82 \%)\end{array}$ & $89(75 \%)$ \\
\hline Daily smoker, n (\%) & $6(2 \%)$ & $5(3 \%)$ & $1(<1 \%)$ \\
\hline Previous smoker, n (\%) & $52(18 \%)$ & $37(21 \%)$ & $15(13 \%)$ \\
\hline Self-reported asthma, n (\%) & 97 (33\%) & $57(32 \%)$ & $40(34 \%)$ \\
\hline Self-reported eczema, n (\%) & $53(18 \%)$ & $30(17 \%)$ & $23(19 \%)$ \\
\hline $\begin{array}{l}\text { Self-reported use of systemic corticosteroids } \\
\text { during last year, } \mathrm{n}(\%)^{1}\end{array}$ & $69(24 \%)$ & $24(14 \%)$ & $45(41 \%)$ \\
\hline \multicolumn{4}{|c|}{$\begin{array}{l}1 \text { Out of those who have used medications against nasal or eye problems during the last year, Total } \\
(n=282) \text {, SLIT }(n=168) \text { Reference population }(n=114)\end{array}$} \\
\hline \multicolumn{4}{|l|}{ Legend for Table 1} \\
\hline
\end{tabular}

\section{Costs}

The mean annual pharmaceutical costs were higher among SLIT patients than among the population controls, $€ 1014$ (Standard Deviation, SD 325) vs $€ 183$ (SD 123, $p<0.001$ ). The reference population patients on the waiting lists had, according to their treating specialist, been subject of standard of care pharmacological treatment optimization. In spite of this, the SLIT group only had mean annual health care costs of $€ 179$ (SD 347) vs $€ 574$ (SD 538, $p<0.001$ ) for the reference patients on the waiting list. The total mean annual direct cost was significantly higher for patients with SLIT, $€ 1191$ (SD 465) than for reference patients, $€ 751$ (SD 581, $p<0.001$ ). The total annual indirect costs for the combined absenteeism and presenteeism were markedly lower for patients treated with SLIT, € 912 (SD 1530), than for reference, $€ 3346$ (SD 4120, $p<0.001$ ), with presenteeism as the main driver (shown in Fig. 2). Altogether, the mean annual total costs were significantly higher for reference patients not treated with SLIT than for the SLIT group; $€ 3907$ (SD 4268) vs. $€ 2084$ (SD 1623), respectively, $p<0.001$. A numerical improvement of quality of life, as measured by EQ-5D-3L, was reported by the patients with SLIT (mean 0.889 ) compared to the reference population (mean $0.847, p=0.072$ ). 


\section{Discussion}

In this study, sublingual immunotherapy was more cost beneficial compared to standard of care pharmacological treatment of seasonal allergic rhinitis, mainly due to reduced indirect costs (absenteeism and presenteeism).

US population-based surveys have estimated the annual number of workdays missed due to AR to be in the range of 0.03 to 0.8 per employed individual per year [13]. Goetzel et al. have, by combining data on work productivity impairment from three large-scale US surveys, concluded that allergy, excluding asthma, was associated with an average $3 \%$ loss of productivity due to work absence and an average $11 \%$ reduction in at-work performance [14]. We have previously investigated the health economic burden attributed to all rhinitis in general as well as AR specifically in the Swedish population. The total annual cost for the former was $€ 2.7$ billion and the later $€ 1.3$ billion $[15,16]$.

The high prevalence of AR makes it clear that even a limited improvement of the therapeutic outcome would significantly ease the socioeconomic burden of this disease on the society. It also important to notice that the present calculation of the economic savings with SLIT is made during the treatment period and that according to previous studies the effect of the therapy will remain far beyond this period thereby further increasing the gains to society. On the other hand, a recent study claims that AIT for grass pollens may be a cost-effective option only in patients with low discontinuation rates and that SCIT, which is less affected by this limitation than SLIT, could be the most cost-effective AIT form [17].

A strength of this study includes the fact that even though an increasing number of studies of AR have included quantitative and validated measures of absenteeism and presenteeism this is, to our knowledge, the first cross-sectional survey that assesses the total, direct and indirect annual costs of SLIT in the treatment of seasonal allergic rhinitis. The fact that this study captured indirect costs due to presenteeism is important, especially as this seems to be a significant part of total costs in individuals with allergic rhinitis.

Some limitations in the method we had to use is that the two comparison groups were not exactly equivalent in some characteristics. EQ-5D could also be considered less sensitive to improvements in health related quality of life than a disease-specific measure, such as the Rhinoconjunctivitis Quality of Life Questionnaire. Furthermore, the retrospective design, i.e. respondents reported allergic symptoms, health-care resource utilization and quality of life for a period back in time, could imply a recall bias which recommends caution when interpreting the results.

\section{Conclusion}

SLIT seems to be a cost-beneficial way to treat seasonal allergic rhinitis, and this information might be used to guide both future recommendations for clinical practice and public health interventions.

\section{Abbreviations}


AR

Allergic rhinitis; SLIT:sublingual Immunotherapy; SCIT:subcutaneous immunotherapy; AIT:allergen immunotherapy; IgE:Immunoglobulin E; FASS:"Farmaceutiska Specialiteter i Sverige” (Pharmaceutical Specialties in Sweden); SD:Standard Deviation; €:Euros

\section{Declarations}

\section{Ethics approval and consent to participate}

Subjects gave their informed consent and the study protocol was approved by the local Ethical committee at Karolinska Institutet, Stockholm, Sweden (Dnr 2016/2158-31/2).

\section{Consent for publication}

Not applicable.

\section{Availability of data and materials}

The datasets used and analysed during the current study are available from the corresponding author on reasonable request.

\section{Competing interests}

P.O. is an employee of Novartis AB and a shareholder of Novartis AG. C.S. has no conflicts of interest to declare. L.A. has received honoraria as a speaker or adviser from AstraZeneca, Meda, Takeda, Teva, Boehinger Ingelheim, MSD, Sanofi and Novartis. F.H. C.S. has no conflicts of interest to declare. K-O.W. has no conflicts of interest to declare. U.W. has no conflicts of interest to declare. M.A. has no conflicts of interest to declare. C .A E. has no conflicts of interest to declare. L-O.C. has received unrestricted grants from ALK Nordic A/S.

\section{Funding}

This study was funded by the Swedish Rhinological Research Alliance (SRFA).

The grant provider, ALK Nordic A/S, of the funder (SRFA) played no part in the study design, data collection, data analysis, data interpretation or writing of the report.

\section{Author Contributions}

Conception and design of the study: P.O., C.S., L-O.C., U.W., K-O.W. and F.H.

Analysis and interpretation of the data: All authors.

Drafting manuscript: P.O., C.S., L-O.C., K-O.W. and F.H.

Preparation of figures and tables: K-O.W. and F.H. 
Review, revision and approval of the manuscript: All authors.

\section{Acknowledgements}

The authors would like to thank Apostolos Bossios, Charlotte Cervin-Hoberg, Anna Drevland, Lena GlantzLarsson, George Grantson, Ann Hammarlund, Kerstin Hansson, Agneta Karlsson, Felicia Larsson, Ulla Nyström, Amanj Saber, Viktoria Strand, Fredrik Sundbom and Helle Thulesius for supporting the distribution and retrieval of the questionnaires.

\section{References}

1. Brozek JL, et al. Allergic Rhinitis and its Impact on Asthma (ARIA) guidelines - 2016 revision. $J$ Allergy Clin Immunol. 2017 Oct;140(4):950-8.

2. Eriksson J, et al. Prevalence of chronic nasal symptoms in West Sweden: risk factors and relation to self-reported allergic rhinitis and lower respiratory symptoms. Int Arch Allergy Immunol. 2011;154(2):155-63.

3. Zuberbier T, Lötvall J, Simoens S, Subramanian SV, Church MK. Economic burden of inadequate management of allergic diseases in the European Union: a GA(2)LEN review. Allergy. 2014;69(10):1275-9.

4. Dhami $S$, et al. Allergen immunotherapy for allergic rhinoconjunctivitis: A systematic review and metaanalysis. Allergy. 2017;72(11):1597-631.

5. Asaria M, et al. Health Economic Analysis of Allergen Immunotherapy (AIT) for the Management of Allergic Rhinitis, Asthma, Food Allergy and Venom Allergy: A Systematic Overview. Allergy. 2018;73(2):269-83.

6. EuroQoL. https://euroqol.org. Accessed 1 Oct 2018.

7. Regional pricing. Södra regionvårdsnämnden, Regionala priser och ersättningar för södra sjukvårdsregionen 2017 www.sodrasjukvardsregionen.se/avtal-priser/regionala-priser-ochersattningar-foregaende-ar Accessed 1 Oct 2018.

8. Pharmaceutical Specialties in. Sweden (FASS). www.fass.se Accessed 1 Oct 2018.

9. Drummond MF, Schulpher MJ, Torrance GW, O'Brien BJ, Stoddart GL. Methods for the Economic Evaluation of Health Care Programmes. Oxford: Oxford University Press, Third edition; 2005. p. 85-6, p. 215-218.

10. Statistics Sweden (SCB). Arbetsinkomst för helårs- och heltidsanställda personer 20-64 år. 2017 www.scb.se/hitta-statistik/statistik-efter-amne/hushallens-ekonomi/inkomster-ochinkomstfordelning/hushallens-ekonomi-hek Accessed 1 Oct 2018.

11. Statistics Sweden (SCB). Konsumentprisindex (KPI). 2018. Accessed 1 Oct 2018.

12. Swedish Economy Facts (Ekonomifakta.se, Sociala avgifter) 2017. Accessed 1 Oct 2018.

13. Schultz AB, Chen CY, Edington DW. The cost and impact of health conditions on presenteeism to employers: a review of the literature. Pharmacoeconomics. 2009;27(5):365-78. 
14. Goetzel RZ, et al. Health, absence, disability, and presenteeism cost estimates of certain physical and mental health conditions affecting U.S. employers. J Occup Environ Med. 2004;46(4):398-412.

15. Hellgren J, Cervin A, Nordling S, Bergman A, Cardell LO. Allergic rhinitis and the common cold-high cost to society. Allergy. 2010;1(6):776-83. 65(.

16. Cardell LO, et al. TOTALL: high cost of allergic rhinitis-a national Swedish population-based questionnaire study. NPJ Prim Care Respir Med. 2016;4:26:15082.

17. Di Bona D, Bilancia M, Albanesi M, Caiaffa MF, Macchia L. Cost-effectiveness of grass pollen allergen immunotherapy in adults. Allergy. 2020. doi:10.1111/all.14246.

\section{Figures}

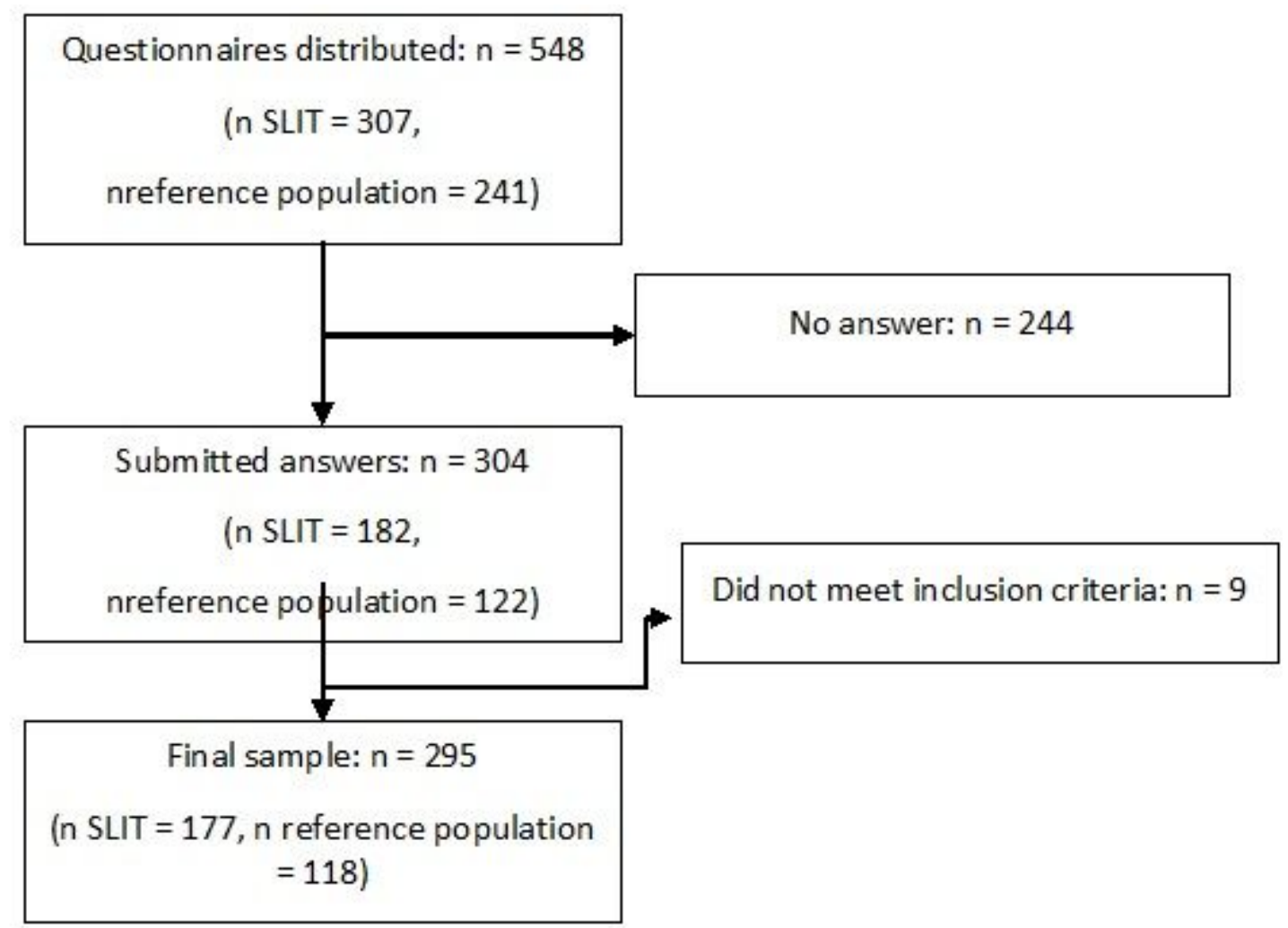

Figure 1

Flow chart of study population 


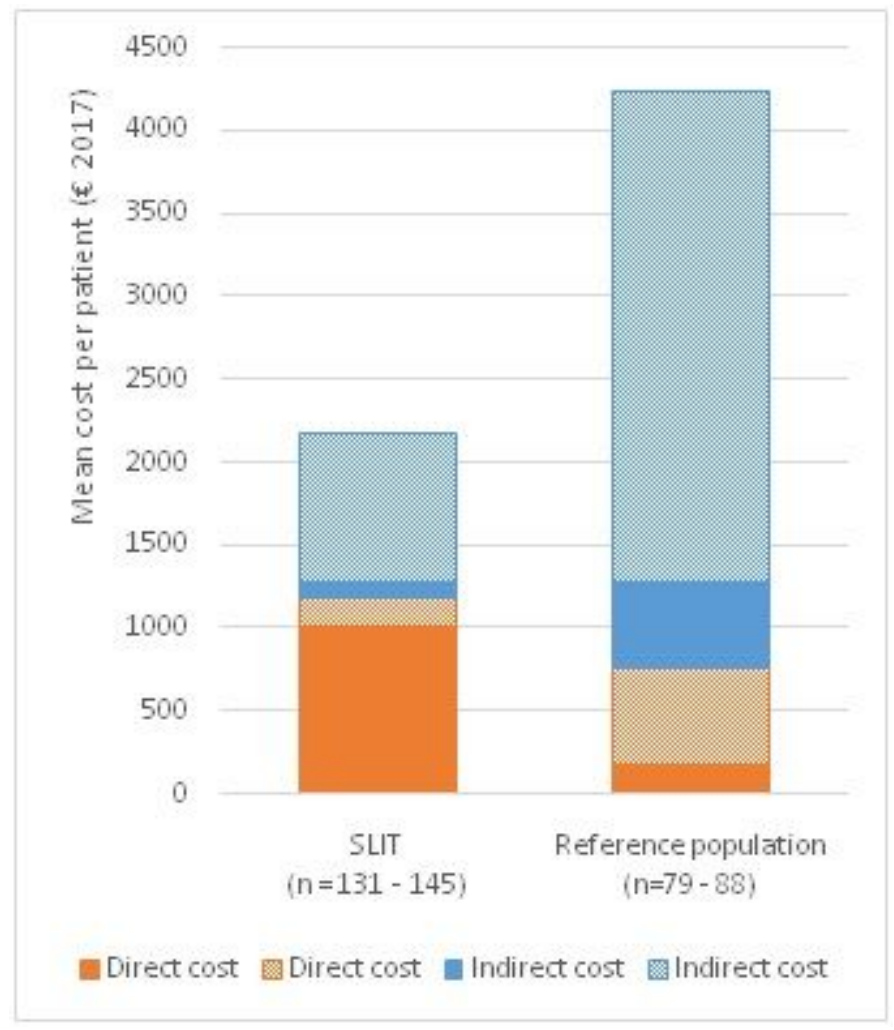

\section{Figure 2}

Direct (pharmaceutical or health care) and indirect costs (absenteeism or presenteeism) by treatment group; $€ 2084$ (SD 1623) for the SLIT group vs $€ 3907$ (SD 4268) for reference population ( $<0.001$ ). SLIT, Sublingual Immunotherapy. Reference population, Standard of care. Mean cost per patient/year.

\section{Supplementary Files}

This is a list of supplementary files associated with this preprint. Click to download.

- OlssonetalSupplementarymaterial1TableE1.docx

- OlssonetalSuppmat2QuestionnaireEngtranslation.docx

- Supplementaryinformation.docx 